\title{
Fungal Colonization and Host Defense Reactions in Ulmus americana Callus Cultures Inoculated with Ophiostoma novo-ulmi
}

\author{
Mirella Aoun, Danny Rioux, Marie Simard, and Louis Bernier
}

First and fourth authors: Centre d'étude de la forêt (CEF), Université Laval, Quebec City, QC, Canada G1V 0A6; and second and third authors: Natural Resources Canada, Canadian Forest Service, Laurentian Forestry Centre, P.O. Box 10380, Sainte Foy, Quebec City QC, Canada G1V 4C7.

Accepted for publication 10 February 2009.

\begin{abstract}
Aoun, M., Rioux, D., Simard, M., and Bernier, L. 2009. Fungal colonization and host defense reactions in Ulmus americana callus cultures inoculated with Ophiostoma novo-ulmi. Phytopathology 99:642650.

The host-pathogen interaction leading to Dutch elm disease was analyzed using histo- and cyto-chemical tests in an in vitro system. Friable and hard susceptible Ulmus americana callus cultures were inoculated with the highly aggressive pathogen Ophiostoma novo-ulmi. Inoculated callus tissues were compared with water-treated callus tissues and studied

and scanning-electron microscopy (SEM). New aspects of this interaction are described. These include the histological observation, for the first time in plant callus cultures, of suberin with its typical lamellar structure in TEM and the intracellular presence of O. novo-ulmi. Expression of the phenylalanine ammonia lyase gene, monitored by real-time quantitative polymerase chain reaction, was correlated with the accumulation of suberin, phenols, and lignin in infected callus cultures. This study validates the potential use of the in vitro system for genomic analyses aimed at identifying genes expressed during the interaction in the Dutch elm disease pathosystem.
\end{abstract} with light microscopy (LM), transmission-electron microscopy (TEM),
During the last century, elm populations worldwide were decimated by two successive pandemics of Dutch elm disease (DED) caused by the ascomycete fungi Ophiostoma ulmi (Buism.) Nannf. and O. novo-ulmi Brasier, respectively. In North America, the highly susceptible Ulmus americana L., one of the most widely planted shade trees in urban areas, suffered heavy damage, with local populations often seriously reduced, for example by up to $80 \%$ in Toronto (23).

Research on the host-pathogen interaction leading to DED and efforts in developing more resistant plant material have been made mostly on elm saplings and trees. For example, the accumulation of mansonone phytoalexins $(16,17)$ and the formation of barrier zones (47) impregnated with suberin, phenolics, and lignin (42) have been proposed as induced mechanisms by which infected elms attempt to stop the spread of the pathogen within their vascular system. Disease-tolerant $U$. americana clones (51) and interspecific hybrids (49) have been obtained through conventional selection and breeding programs (28).

In vitro systems based on callus and suspension cultures have also been used for the study of DED. These provide a more controlled environment, make it possible to analyze one factor at a time all year long, and facilitate manipulation of both host and pathogen. Investigators have relied on elm callus culture for rapid screening of resistant host genotypes or aggressive isolates of the pathogen $(11,14,37,45)$. The use of elm tissue culture has also brought insights into some aspects of the host-pathogen interaction. Microscopic observations of fungal growth in inoculated callus culture showed the occurrence of a dense hyphal network and intensive conidia formation in susceptible $U$. americana callus tissue $(15,26)$. The latter exhibited mitochondrial and cytoplasmic disruptions as well as extensive vacuolation and plasmo-

Corresponding author: L. Bernier; E-mail address: Louis.Bernier@sbf.ulaval.ca

doi:10.1094/PHYTO-99-6-0642

(C) 2009 The American Phytopathological Society lysis, whereas resistant callus tissues were characterized by heavy deposition of starch grains and electron-opaque material thought to be phenolic-like $(26,38)$. Mansonone phytoalexins were also shown to accumulate in elm callus tissue treated with either fungal inoculum (18) or culture filtrates (58). Analysis of the latter led to the identification of a glycoprotein mansonone-inducing elicitor in both $O$. ulmi and $O$. novo-ulmi (57). Using elm suspension cultures, Corchete et al. (9) also showed that inoculation of DED-resistant $U$. pumila with spores of $O$. ulmi induced an increase in phenylalanine ammonia lyase (PAL) activity, whereas no stimulation was observed in the susceptible $U$. campestris.

A large-scale genomic analysis of O. novo-ulmi is currently underway (2). The objective of this study was to establish the suitability of callus cultures as an experimental system for facilitating the genomic study of the interaction between the susceptible $U$. americana and yeastlike cells of the aggressive pathogen O. novo-ulmi. Analyses included microscopic observations of fungal colonization of callus tissues, histochemical characterization of elm cell responses to fungal infection, and transcript profiling of the PAL gene, which was selected as a molecular marker for defense reactions.

\section{MATERIALS AND METHODS}

Plant tissue culture. Stable hard and friable callus lines were grown from the DED-susceptible species $U$. americana. Hard callus cultures were initiated from buds collected in May 2003 from a single tree on the Université Laval campus (Québec, QC, Canada). Explants were treated according to Yang and Bernier (56). Friable callus cultures were initiated from mature seed collected in June 2001 near trees also located on the campus. After seed germination, cotyledons and hypocotyls were soaked for $20 \mathrm{~min}$ in a solution of $0.5 \%$ sodium hypochlorite and $0.01 \%$ Tween 20 and rinsed three times with sterile distilled water. Explants were cultured on modified Murashige and Skoog (MS) medium (31) (Sigma-Aldrich, St. Louis, MO) (catalog no. 
M5519, $4.4 \mathrm{~g} /$ liter) supplemented with 3\% (wt/vol) sucrose, $5.4 \mu \mathrm{M}$ naphthaleneacetic acid (Sigma-Aldrich), $4.4 \mu \mathrm{M}$ benzyl adenine (Sigma-Aldrich), and $0.48 \%$ (wt/vol) Agargel (SigmaAldrich), as described by Eshita et al. (19). Cultures were incubated in the dark at $23^{\circ} \mathrm{C}$ and subcultured to fresh medium every 4 (friable callus cultures) or 6 weeks (hard callus cultures).

Inoculations. The aggressive $O$. novo-ulmi subsp. novo-ulmi isolate H327 (20) was used in this study. Budding cells were produced by incubating a 2-mm mycelium disk in Ophiostoma liquid minimal medium (3) supplemented with L-proline (1.15 g/liter). After 3 days of incubation at 23 to $24^{\circ} \mathrm{C}$ with shaking (120 to $170 \mathrm{rpm})$, the cells were filtered through cheesecloth, centrifuged at $4,500 \times g$ for $5 \mathrm{~min}$, and resuspended in sterile distilled water at a concentration of $2 \times 10^{6}$ budding cells/ml (14). A final transfer of $40-\mathrm{mm}^{2}$ callus pieces on 5 -cm-diameter petri dishes containing $10 \mathrm{ml}$ of fresh MS medium was made 11 days prior to inoculations (26). Callus inoculation with either sterile water or fungal cells were made as follows: a 6-mm-diameter blank paper disk (Becton Dickinson, Sparks, MD) was cut in half, sterilized by autoclaving, soaked with $20 \mu \mathrm{l}$ of either fungal inoculum or water, air-dried in a laminar flow cabinet, and placed at the center of the top portion of the callus. Additional controls included inoculum or water disks placed on sterile Ophiostoma complete medium (3) and modified MS medium (19) over a cellophane membrane.

Tissue processing for microscopy. Three friable callus lines and one hard callus line were used for microscopy. Samples from each line were taken at $24,48,72$, and $96 \mathrm{~h}$ postinoculation (hpi). For each time, one infected callus from each line was fixed and controls were taken $96 \mathrm{~h}$ following inoculation with sterile water. Different parts of a callus were fixed to estimate the extent of colonization by the fungus. Samples were fixed with $3 \%$ glutaraldehyde and $2 \%$ formaldehyde in $0.1 \mathrm{M}$ sodium cacodylate buffer (SCB) ( $\mathrm{pH} 7.4)$ under vacuum for $2 \mathrm{~h}$, rinsed in the same buffer, and post-fixed with $1 \%$ osmium tetroxide $\left(\mathrm{OsO}_{4}\right)$ in $0.1 \mathrm{M}$ $\mathrm{SCB}$ for $1 \mathrm{~h}$ under vacuum. After dehydration in ethanol series, samples were embedded in JEMBED 812 resin (Canemco Inc., Montréal, Québec). For light microscopy (LM), sections $(1 \mu \mathrm{m})$ were obtained with an Ultracut E microtome (Reichert-Jung, Vienna, Austria), stained with $2 \%$ toluidine blue $\mathrm{O}$ followed by $1 \%$ safranin O (41), and observed with a Polyvar light microscope (Reichert-Jung). For transmission electron microscopy (TEM), ultrathin sections $(90 \mathrm{~nm})$ were contrasted with uranyl acetate and lead citrate (39) (Fisher Scientific International, Fairlawn, NJ) and examined with a Philips 300 (Eindhoven, The Netherlands) electron microscope operating at $80 \mathrm{kV}$. For scanning electron microscopy (SEM), samples were processed as for TEM. In addition, samples were dehydrated in hexamethyldisilazane (SigmaAldrich), and sputter-coated with gold before examination with a JEOL JSM6360LV microscope (JEOL USA Inc., Peabody, MA) at $10 \mathrm{kV}$.

For histochemical tests, samples were fixed in $4 \%$ formalin diluted in $0.1 \mathrm{M}$ phosphate buffer $(\mathrm{pH}$ 7.4) and dehydrated in ethanol series. Ethanol was gradually replaced by Protocol Safeclear (Fisher Scientific, Middletown, VA) and the samples were thereafter placed in pure Paraplast (Oxford Labware, St. Louis, $\mathrm{MO}$ ) for 3 days at $65^{\circ} \mathrm{C}$, with replacement every $24 \mathrm{~h}$. Longitudinal sections $(5 \mu \mathrm{m})$ were obtained with a Jung 2035 rotary microtome (Heidelberg, Germany), deparaffined, and processed as described below. For detection of suberin, sections were treated with phloroglucinol- $\mathrm{HCl}$, which stains lignin red and masks its autofluorescence, and examined under ultraviolet light (UV) excitation (4) using a BP 330 to 380 exciter filter with a DS 420 separator mirror and an LP 418 barrier filter. Sudan black staining (24) was carried out on some sections as additional evidence of suberin deposition. The number of suberized cells was calculated under UV light after phloroglucinol- $\mathrm{HCl}$ staining. The total number of cells and the number of suberized cells were counted in 10 optical fields taken randomly at $\times 40$ magnification; hence, for each section, at least 1,000 cells were counted. For detection of condensed tannins, sections were immersed in $0.1 \%$ 4-dimethylaminocinnamaldehyde (DMCA) and $0.5 \mathrm{M}$ sulfuric acid in butanol) for $2 \mathrm{~min}$ (52). Tannins such as pro-anthocyanidins, appeared dark blue or blue-green. Less condensed tannins (oligomers) and monomers, such as catechins, were stained red after immersion for $5 \mathrm{~min}$ in a solution of $10 \%$ vanillin in one volume of absolute ethanol and one volume of concentrated $\mathrm{HCl}$ (52).

For TEM, the lamellar structure of suberized layers was made more obvious by contrasting the sections with $1 \% \mathrm{OsO}_{4}$ followed by a mixture of one volume of $2 \%$ uranyl acetate $\left(\mathrm{UO}_{2} \mathrm{Ac}\right)$ and one volume of $1 \%$ potassium permanganate $\left(\mathrm{KMnO}_{4}\right)(53)$. Cellulose molecules were labeled with an exoglucanase (EC 3.2.1.91, provided by $\mathrm{C}$. Breuil, University of British Columbia, Vancouver, BC, Canada) having an affinity with $\beta$ - $(1,4)$-D-glucans. The enzyme was gold-complexed and used according to Nicole et al. (33). Ultrathin sections were floated on a drop of $0.01 \mathrm{M}$ phosphate buffered saline (PBS) $(\mathrm{pH}$ 6.5) containing $0.02 \%$ polyethylene glycol 20,000 for $10 \mathrm{~min}$, and then incubated with the exoglucanase gold complex for $30 \mathrm{~min}$. Before contrasting with uranyl acetate and lead citrate for examination in TEM, sections were rinsed with PBS, and thereafter with filtered distilled water. Control tests were carried out using the enzyme gold complex previously adsorbed with $\beta$-(1,4)-D-glucans.

Quantitative reverse transcription-polymerase chain reaction. Elm translation initiation factor 5A (EIF5A) was used as a reference gene to monitor the expression of the elm PAL gene. An EIF5A expressed sequence tag (EST) designated C2-F8 was obtained from a subtractive cDNA library constructed in our laboratory. The nucleotide sequence is available in the GenBank EST database under the accession number FC325680. A partial cDNA sequence from a $U$. americana PAL mRNA was obtained from the GenBank nucleotide database under the accession number DQ078279. These two cDNAs sequences (FC325680 and DQ078279) were used to develop quantitative reverse transcription-polymerase chain reaction (qRT-PCR) primers (EIF5AF: 5'GTTTTGCTGAGGGAAAAGACTTGGT-3'; EIF5AR: 5'-AACGCTACCAAAGGCATACTTGTGA-3'; product size: 217 bp; PALF: 5'-TGCCCAAAGAAGTTGAGAGTTCAAG-3'; PALR: 5'-AGTCCCCAATTCCTCTCTCACAAAC-3'; product size: 122 bp).

Hard callus cultures were inoculated with either fungal cells or water as described previously and harvested in liquid nitrogen at 4, 24, 48, 72, 96, and 144 hpi. There were three replicates per treatment and each treatment was composed of three callus samples weighting between 130 and $170 \mathrm{mg}$ each and harvested together. In addition, three healthy callus samples were harvested at the beginning of the experiment $(0 \mathrm{hpi})$ as an additional control. Five hundred nanograms of total RNA from each sample was extracted according to Chang et al. (8) and used for first-strand cDNA synthesis with SuperScript II Reverse transcriptase (Invitrogen, Carlsbad, CA) with oligo $(\mathrm{dT})_{12-18}(500 \mu \mathrm{g} / \mathrm{ml})$ according to the manufacturer's instructions. These cDNAs were diluted 1:5 in sterile water prior to real-time PCR quantification.

The absence of genomic contamination was verified by running all RNA samples in the same run with cDNA samples. No amplification was detected with RNA samples. Quantitative RT-PCR was performed using a 7500 real-time PCR system (Applied Biosystems, Foster City, CA) and the QuantiTect SYBR PCR kit (Qiagen Inc., Mississauga, ON, Canada). The three biological replicates were run on the same plate. All qRT-PCR reactions contained cDNA equivalent to $10 \mathrm{ng}$ of total RNA. Amplifications were performed in a $15-\mu$ l reaction volume in $2 \times$ QuantiTect SYBR Green mixture (Qiagen) with $0.3 \mu \mathrm{M}$ of $5^{\prime}$ and $3^{\prime}$ primers. After an initial 15 -min activation step at $95^{\circ} \mathrm{C}, 40$ cycles $\left(94^{\circ} \mathrm{C}\right.$ for $10 \mathrm{~s}, 62^{\circ} \mathrm{C}$ for $2 \mathrm{~min}$ ) were performed, and a single fluorescent reading was obtained after each cycle immediately following the 
annealing and elongation step at $62^{\circ} \mathrm{C}$. A melting curve was analyzed at the end of cycling to ensure that there was a single amplification product. Threshold cycle $\left(\mathrm{C}_{\mathrm{T}}\right)$ values were determined with the software supplied with the instrument. Standard curves generated using cDNA clones as templates were used to transform $\mathrm{C}_{\mathrm{T}}$ values obtained from total RNA samples into transcript numbers. PAL samples were normalized with EIF5A samples.

Statistical analysis. Statistical analyses were done with SAS version 9.1 Software (SAS Institute Inc., Cary, NC). Analysis of variance (ANOVA) according to general linear models procedure and Tukey's tests were used to analyze qRT-PCR data. For all analyses, when normality or homogeneity of residues was not respected, data were first transformed by rank.

\section{RESULTS}

Fungal development. When plated directly onto MS medium, budding cells of $O$. novo-ulmi $\mathrm{H} 327$ developed into mycelial colonies that reached only half of the $8.5-\mathrm{cm}$-diameter petri dishes, even when left for up to 50 days in culture. In contrast, it took the fungus only 4 days to fill dishes containing Ophiostoma complete medium. When examined by SEM, few or no conidia
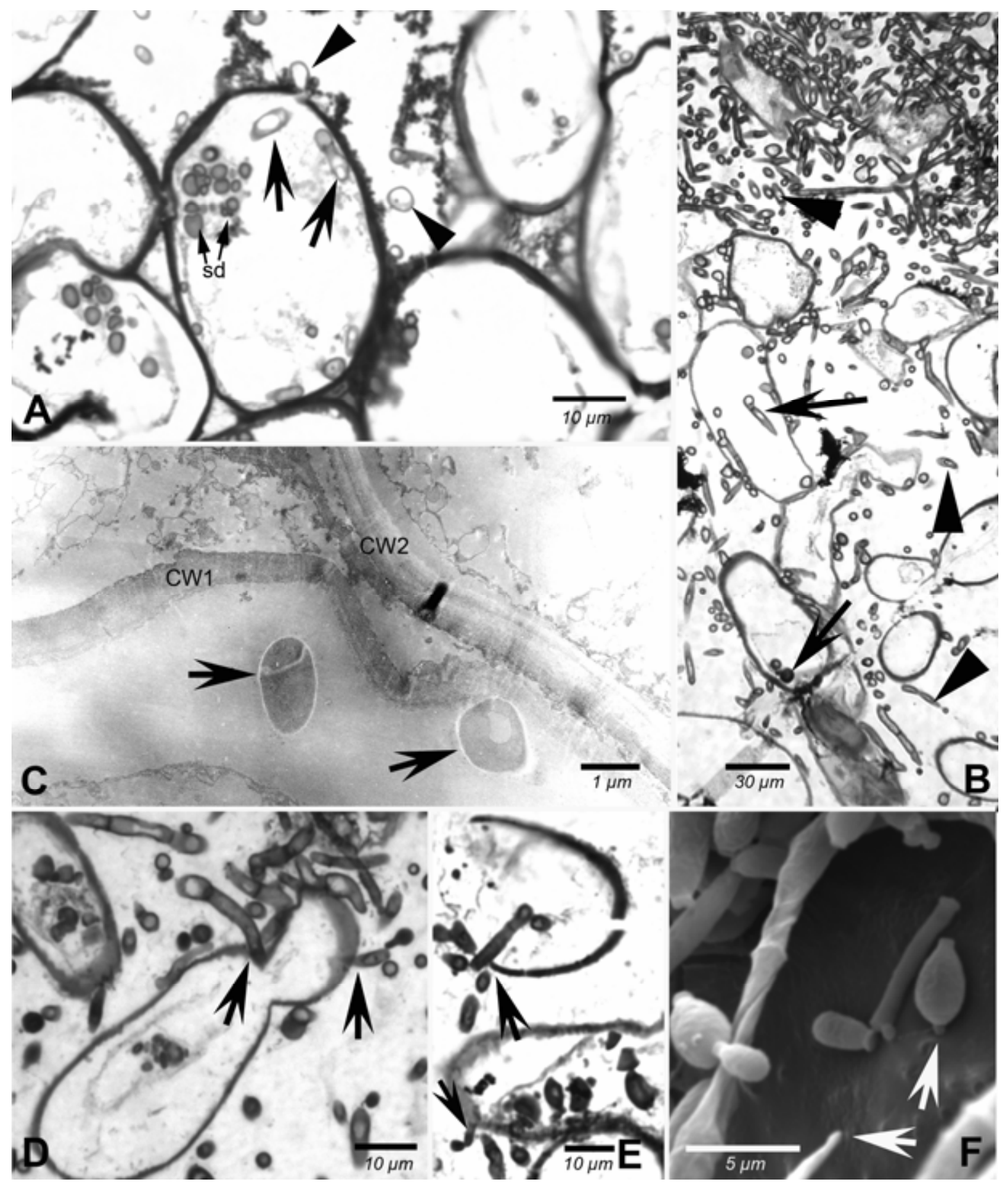

Fig. 1. Fungal development in Ulmus americana callus cultures inoculated with Ophiostoma novo-ulmi. A and B, Presence of pathogen cells at the center of friable callus samples at 48 and $96 \mathrm{~h}$ postinoculation (hpi), respectively. The fungus is mainly observed in intercellular spaces (arrowheads), but its intracellular presence (arrows) is also shown; sd: starch deposits. C, In transmission electron microscopy (TEM), two fungal cells (arrows) are clearly visible in a host cell. Sections from the center of a hard callus at 48 hpi. CW1 and CW2: walls of two callus cells. D to F, Penetration of elm callus cell walls by the pathogen (arrows) as observed in friable callus samples in light microscopy at $72 \mathrm{hpi}(\mathbf{D})$ and $96 \mathrm{hpi}(\mathbf{E})$ and in scanning electron microscopy on the surface of a hard callus at 48 hpi (F). 
were observed on hyphae from MS media. The fungus developed more extensively on elm callus than on MS medium. Budding cells germinated into hyphae with typical morphology, such as those bearing conidia. Mycelium and spores were seen in all parts of the inoculated callus by $48 \mathrm{hpi}$, for both types of callus tissue. By $96 \mathrm{hpi}$, the fungus had reached the medium in the plate, the color of the callus had changed to yellow, and necrosis was seen under the inoculation point. In the water-treated hard and friable callus tissues, all cells kept a healthy appearance except occasionally for an area just under the disk, indicating cell damage or a reaction to the presence of the disk.

Fungal colonization (Fig. 1A to $\mathrm{C}$ ) of the callus took place mostly in intercellular spaces, the fungus being more abundant in friable callus where empty spaces were larger and more numerous (Fig. 1B). However, intracellular presence of the fungus was also observed in both types of callus tissues by light (Fig. 1A and B) and electron microscopy (Fig. 1C). Direct penetration of the host cell wall was occasionally observed (Fig. 1D to F).

Callus morphology and reactions. The main structural difference observed between healthy friable and hard callus tissues was the organization of the cells. In friable callus tissue, cells were dissociated and loose with many intercellular spaces, whereas in hard callus tissue cells were grouped in closely packed layers leaving almost no space between the cells. No important differences were noted in the histopathology of the three friable callus lines used in the study, and the cell reactions described in this section were found in both types of callus tissue, friable and hard, unless otherwise stated. Phenolic and starch deposits were more abundant in inoculated callus samples than in controls. This deposition was seen by $48 \mathrm{hpi}$, particularly in layers of cells located just beneath the front line of dead cells in direct contact with the fungus (Figs. 2A to $\mathrm{C}$ and $3 \mathrm{~A}$ ). Positive vanillin tests confirmed the phenolic nature of these opaque deposits and showed the abundance of less condensed tannins, such as catechins, in infected callus tissues (Fig. 3B). More condensed tannins detected through the DMCA test became evident only at 96 hpi (data not shown).

Suberization and lignification of cell walls were especially apparent in hard callus. The light-blue autofluorescence emitted by suberin was conspicuous under UV illumination, particularly after quenching lignin autofluorescence with phloroglucinol-HCl (Fig. 3C). Staining with Sudan black B and phloroglucinol-HCl confirmed the presence of suberin in these cells as well as that of lignin in the walls of many adjacent cells (Fig. 3D). In electron microscopy, cell wall reinforcements and alterations were also evident, mainly in the vicinity of fungal cells (Fig. 4). In TEM, the exoglucanase gold labeling was a means to help localize suberized layers as most of these were nearly devoid of gold particles while adjacent layers were often strongly labeled (Figs. $2 \mathrm{C}$ and 4A). After contrasting the sections with $\mathrm{OsO}_{4}$ and $\mathrm{UO}_{2} \mathrm{Ac} / \mathrm{KMnO}_{4}$, the typical presence of electron-opaque and electron-translucent lamellae within suberized layers became particularly evident (Fig. 4B). The proportion of suberized cells, as determined under UV light microscopy, was higher in callus samples inoculated with $O$. novo-ulmi than in water-treated callus samples (Fig. 5). At 96 hpi, the former showed a 4.6-fold increase over the latter.

Cell wall degradation was especially obvious in callus cells in close contact with fungal hyphae (Fig. 4C to E). Even when $O$. novo-ulmi cells were not detected close to the wall, in those callus areas where degradation was prominent, the exoglucanase gold labeling in TEM frequently revealed that cellulose was apparently degraded within certain host wall areas (Fig. 4F). The impact of the pathogen on cell walls was also obvious in SEM (Fig. 4G) with collapsed cells in infected callus when compared with control callus (Fig. 4H) in which cells were turgescent.

PAL gene expression. Transcript accumulation of the PAL gene was monitored over time in water-treated and fungalinoculated callus cultures (Fig. 6). This monitoring covered 4 to
144 hpi and included the time points chosen for microscopic observations. Healthy callus samples harvested at the start of the experiment $(0 \mathrm{hpi})$ were chosen as controls. PAL expression was relatively stable in water-treated callus samples and it did not exceed 1.5 times (48 hpi) the level observed in healthy callus sample, whereas it varied from 1.3 (24 hpi) to 7.2 (144 hpi) times in callus samples inoculated with $O$. novo-ulmi. Absolute quanti-

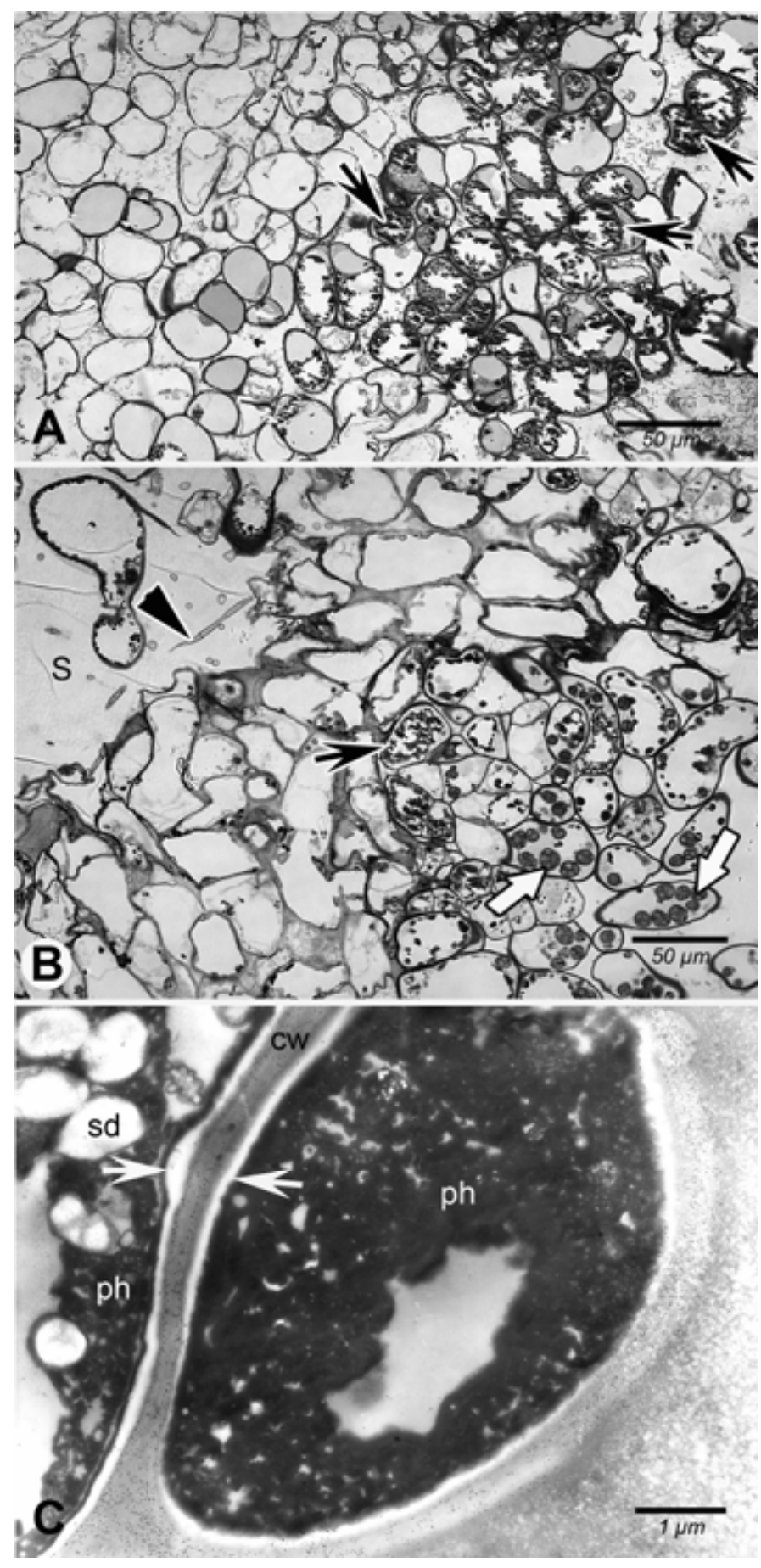

Fig. 2. Phenol accumulation and starch deposits in Ulmus americana callus cells after inoculation with Ophiostoma novo-ulmi. A and B, Friable callus samples at 48 and $72 \mathrm{~h}$ postinoculation (hpi), respectively. Phenols (black arrows) appear dark-stained with toluidine blue. Starch grains (B, white arrows) are obvious in host cells located just beneath the front line of dead cells in direct contact with the fungus (arrowhead) at the surface (S) of the callus. C, Electron-opaque phenolic-like material (ph) adjacent to translucent suberized wall layers (arrows) in host cells of a hard callus at $72 \mathrm{hpi}$. The exoglucanase-gold labeling is intense over the host cell wall (cw) while it is virtually absent over the suberized layers; sd: starch deposit. 
fication enabled us to calculate the number of transcripts in each sample. In healthy callus sample, the average number of PAL mRNA molecules per nanogram of total RNA was 536. At 96 hpi, the latest time point of microscopic observations, this number was 785 in water-treated callus sample, whereas it had reached 1,950 molecules in inoculated callus sample. Significant difference in PAL gene expression between water-treated and fungal-inoculated callus samples started at $72 \mathrm{hpi}$ according to statistical analysis ( $F$ was significant at $P=0.033$ ).

\section{DISCUSSION}

The purpose of this study was to analyze and validate an in vitro system that would reflect the interaction leading to DED in order to identify genes involved in this interaction using genomic tools. Histopathological observations showed the accumulation of suberin, phenols, lignin, and starch in $U$. americana callus cultures inoculated with O. novo-ulmi. Results also shed more light on the colonization of elm tissue by the fungus, particularly the direct penetration of cell walls accompanied by partial degradation of cellulose. These observations likely reflect changes in the levels of gene expression in both host and pathogen. We detected significant changes in PAL transcript levels in association with the defense responses. Overall, our results show that this in vitro system is a valuable tool for future genomic studies, and revealed the importance of newly observed mechanisms in the development of the DED pathogenic interaction.

O. novo-ulmi $\mathrm{H} 327$ exhibited the same pattern of development on fungal growth medium and on elm callus. By $48 \mathrm{~h}$, yeastlike cells had germinated into hyphae that were sporulating into conidia, and normal mycelial growth continued with time. This

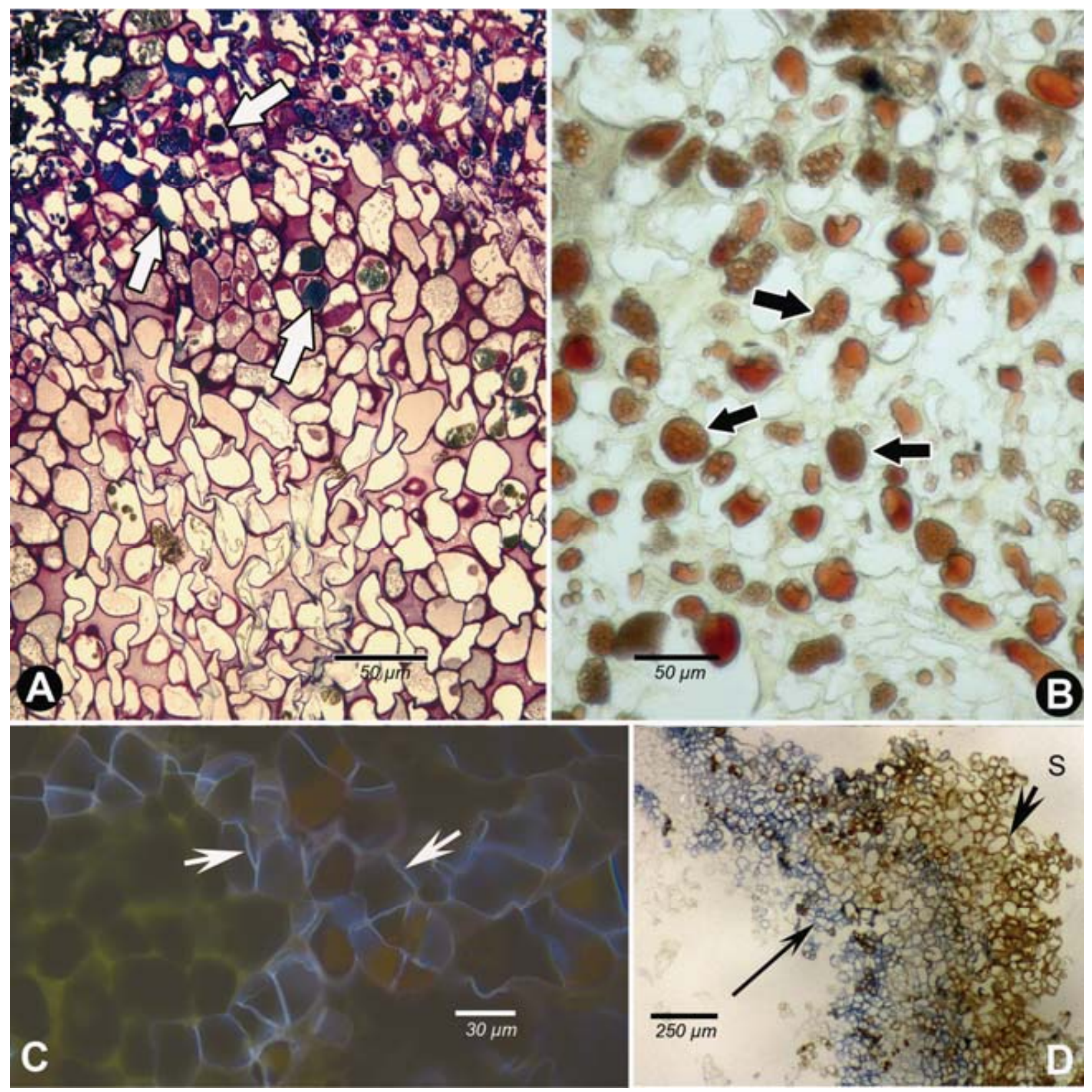

Fig. 3. Defense reactions in hard Ulmus americana callus cultures inoculated with Ophiostoma novo-ulmi. A, Cells rich in phenols (arrows) stained blue with toluidine in this sample collected at $72 \mathrm{~h}$ postinoculation (hpi) on the surface of this callus. B to D, Histochemical tests revealing the chemical nature of some of the cell defense reactions. B, Heavy accumulation of tannin oligomers and monomers (e.g., catechins) stained in red (arrows) using the vanillin test at 96 hpi. C, Suberin autofluorescence (arrows) revealed under UV illumination in a section previously stained with phloroglucinol- $\mathrm{HCl}$ at $48 \mathrm{hpi}$. D, Lignified cells (short arrow) at the surface (S) of this callus at 48 hpi appear brownish red after staining with phloroglucinol-HCl, whereas suberized cells (long arrow) formed more internally are stained dark blue with Sudan black B. 


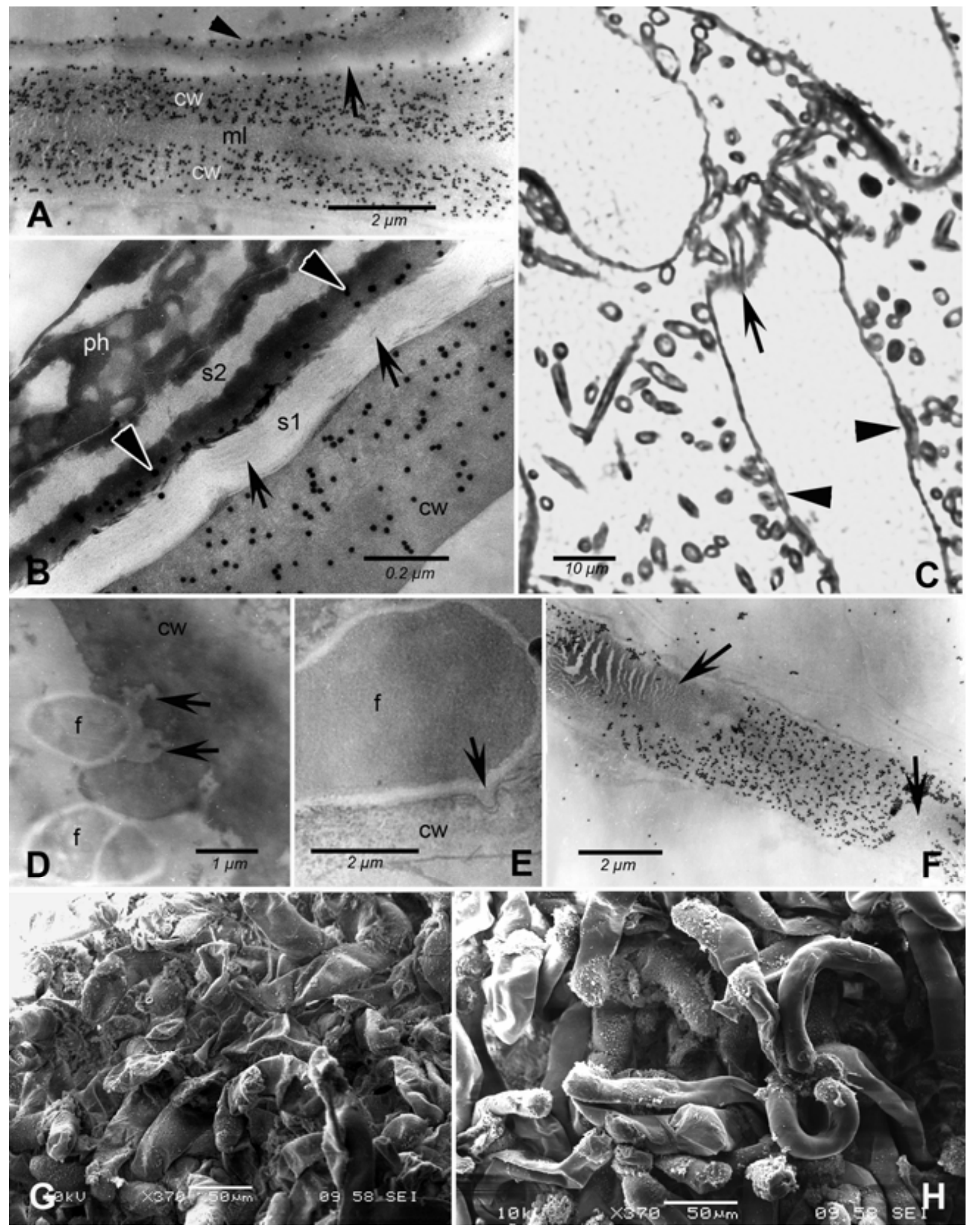

Fig. 4. Cell wall modifications in Ulmus americana callus cultures inoculated with Ophiostoma novo-ulmi. A and B, Suberized cell wall layers (arrows) are shown next to primary cell walls (cw) intensely labeled with the exoglucanase-gold complex in these hard callus cells at $48 \mathrm{~h}$ postinoculation (hpi). Note the formation of another wall layer (arrowheads) labeled with the exoglucanase-gold complex internally to the first suberized layer; ml: middle lamella. B, A second suberized layer is also seen (s2). The typical lamellar structure of suberin is evident (arrows) in the thicker layer after contrasting with $\mathrm{OsO}_{4}$ and $\mathrm{UO}_{2} \mathrm{Ac}_{\mathrm{KMnO}}$. $\mathrm{Phenol-like} \mathrm{(ph)}$ material is present in the cytoplasm. $\mathbf{C}$ to $\mathbf{E}$, Degradation of host cell walls in contact with fungal cells. $\mathbf{C}$, In light microscopy, the wall appears eroded (arrow) or deteriorated (arrowheads) close to pathogen cells in this friable callus at $96 \mathrm{hpi}$. D to E, In transmission electron microscopy (TEM), the host cell wall (cw) appears strongly degraded (arrows) next to fungal cells (f); (D) at the center of a friable callus at 96 hpi and (E) on the surface of a friable callus at 48 hpi. F, In TEM, the absence of labeling with the exoglucanase-gold complex (arrows) suggests that cellulose was degraded in certain areas of the host cell wall even though no pathogen cells were seen contiguous to the wall in this hard callus at 72 hpi. $\mathbf{G}$ to $\mathbf{H}$, In scanning electron microscopy, the cells of the infected friable callus (G) are collapsed and the walls appear degraded and show a rough appearance while cells of the control (H) appear turgescent and the walls present a smoother appearance. Samples collected in both callus samples at $96 \mathrm{hpi}$. 
was not the case on the MS medium alone, where fungal growth was slow and conidia were absent. We can therefore conclude that the development of the fungus in infected callus tissues reflects the susceptibility of the latter rather than the contribution of the growth medium.

O. novo-ulmi is known to colonize the vascular system mainly through direct penetration of pit membranes and intercellular spaces in the xylem of elm trees during its pathogenic phase (7). While this pattern of development is also observed in callus tissue (i.e., development in different directions with a tendency to occupy mainly empty spaces), direct penetration of elm cell walls did occur. Based on SEM observations, Krause et al. (26) suggested that hyphae of $O$. novo-ulmi were able to penetrate cells of susceptible American elm callus tissues. Our micrographs provide the first evidence of the presence of $O$. novo-ulmi hyphae inside $U$. americana callus cells. In elm trees infected with DED, the presence of $O$. novo-ulmi cells inside living cells has only been reported in rare instances (35). We also showed that $O$. novo-ulmi was able to directly penetrate host cell walls and that the area in close contact with the fungus was clearly degraded. This suggests that the pathogen possesses and secretes cell wall degrading enzymes that facilitate the colonization of host tissue, as already hypothesized by others for the in vivo interaction $(44,54)$.

This study compared different lines of callus cultures and is the first to consider and compare the responses of two types of elm callus tissues, i.e., friable and hard. An important finding was that the response of elm callus to inoculation included the production of suberin which, in DED literature, had only been reported in saplings (21) and trees $(40,42,43)$. Furthermore, observations in TEM allowed us to distinguish the typical lamellar structure of suberin. To our knowledge, this is the first time that suberin lamellae are described in a plant callus tissue. The presence of suberin was previously suggested in callus tissues from Sitka spruce challenged with wood decay fungi (55), anthracnose-resistant alfalfa (29), and grapevine resistant to downy mildew (10). These reports, however, were only based on the observation in resistant tissues of a positive reaction with Sudan dyes, which are specific to lipid-containing molecules, such as cutin and suberin, and did not include ultrastructure and fluorescence micrographs. Besides revealing the typical structure of suberin in callus tissues, our results also showed that susceptible callus tissues are able to produce suberin as a defense mechanism and that noninfected tissues contain suberin as well. But, while suberin was detected in both noninfected and infected susceptible callus tissues, it accumulated to a larger extent in the latter. From the time the fungus had germinated in infected callus (48 hpi) to the final sampling time (96 hpi), the proportion of suberized cells was almost five times higher in inoculated than in water-treated callus. This shows

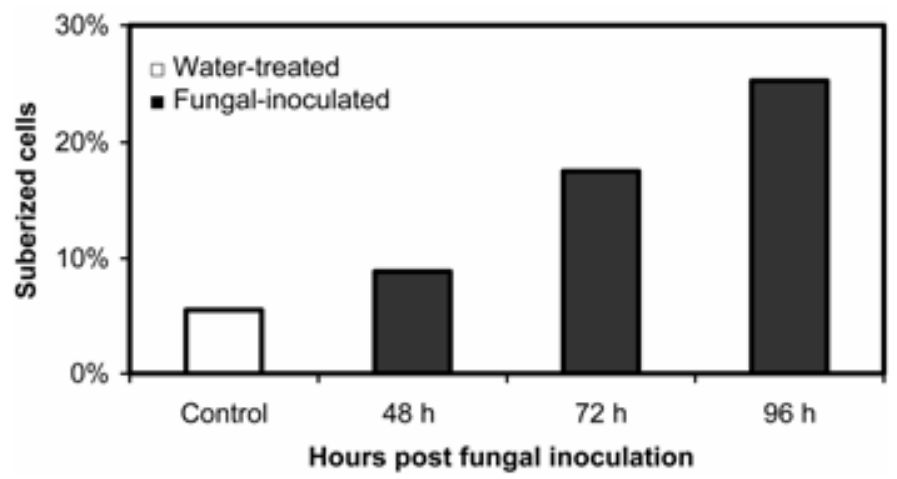

Fig. 5. Proportion of suberized cells in Ulmus americana callus tissues inoculated with Ophiostoma novo-ulmi. Cells were counted in infected callus samples at 48, 72, and $96 \mathrm{~h}$ postinoculation (hpi), and in a water-treated control callus at 96 hpi. that suberin accumulation is stimulated by the presence of the fungus, and that this biotic stress is greater than the abiotic stress resulting from subculturing, wounding, or water application.

Suberin has previously been associated with defense reactions in adult $U$. americana trees affected by DED. Rioux and Ouellette $(42,43)$ showed that barrier zones of annual shoots and small branches of $U$. americana infected with $O$. novo-ulmi frequently contained suberized parenchyma cells, and at times suberized fibers. In addition, Rioux et al. (40) observed that tyloses formed in the xylem of infected $U$. americana trees had internal suberized layers. The formation of more than one suberized layer, close to phenols and cellulosic wall layers, as shown in Figure 4B, has also been reported in trees $(40,43)$. Thus, it appears that callus and parenchyma tissues, as well as cells in a differentiating mode (e.g., cambial derivatives), share the capacity to produce suberin. Although the lack of structure in callus makes suberin deposition less organized than in whole plants, the finality of the process is most likely the same (i.e., to restrict exchanges with the medium outside of healthy cells that are not in the front line or in direct contact with the fungus). For instance, in Figure 3D, the presence of lignified cells adjacent to a suberized layer is somewhat reminiscent of what happens in trees. When the bark is injured, it is well known that a lignified impervious tissue is formed just before the differentiation of a suberized necrophylactic periderm (30). This fact was confirmed many times, even though it has been shown that the lignified cells also contain a thin internal suberized layer (e.g., described in Biggs [4,5]). The presence of lignified cells contiguous to that of suberized tissues has also been reported in defensive xylem tissues of broad-leaved trees and conifers $(42,48)$.

PAL is a key enzyme controlling the biosynthesis of phenolics in plants (50). It is induced in response to wounding and infection by plant pathogens (25) and is associated with the accumulation of suberin in plants $(1,22,27,34)$. Our measurements of PAL gene expression confirmed this association in elm callus inoculated with $O$. novo-ulmi, as patterns for suberization and PAL expression followed similar trends. PAL seems to be constitutively expressed (536 RNA transcripts per nanogram of total RNA) in healthy callus sample, yet its association with fungal infection was also apparent. The significant increase in PAL expression observed at $72 \mathrm{hpi}$, and thereafter in inoculated but not in water-

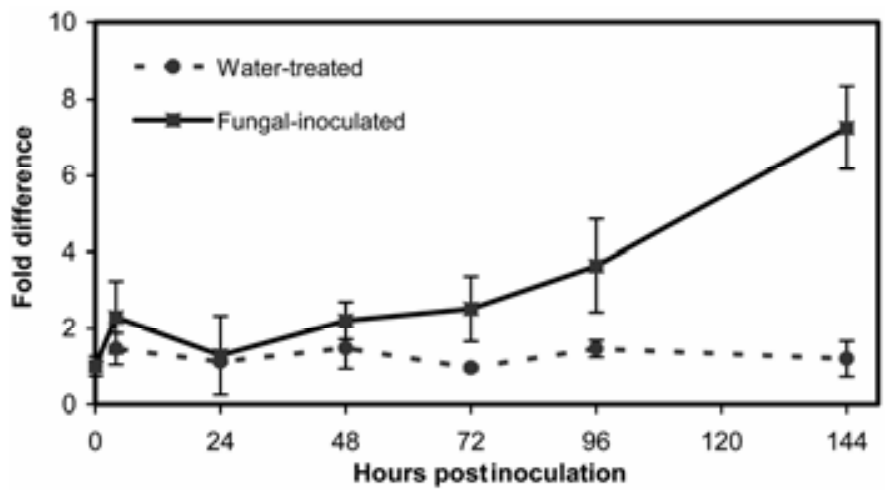

Fig. 6. Fold difference in phenylalanine ammonia lyase (PAL) gene expression in water-treated and fungal-inoculated Ulmus americana callus cultures. The number of PAL mRNA molecules in water-treated and fungal-inoculated (Ophiostoma novo-ulmi) callus samples was calculated at six time points after inoculation $(4,24,48,72,96$, and $144 \mathrm{~h}$ postinoculation [hpi]) and compared with that in healthy callus samples collected at 0 hpi. PAL samples were normalized with Elm translation initiation factor 5A (EIF5A) samples. Error bars were drawn based on the calculation of the standard deviation for the three biological replicates used in the study for each treatment. To calculate the number of molecules, absolute quantification was used and the trendline equation and $R^{2}$ value for each gene were as follows: EIF5A: $y=-0.298 x+$ 9.61; $R^{2}=0.99$; amplification efficiency: 99.3\%; PAL: $y=-0.3001 x+10.249$; $R^{2}=1$; amplification efficiency: $99.8 \%$. 
treated callus samples was evidence of its induction by the infection and seems to be directly associated with the development of the fungus inside the callus. This result confirms a recent observation by Nasmith et al. (32) who, based on RNA dot blot analysis, reported an increase in PAL expression in leaf midribs of $U$. americana saplings inoculated with $O$. novo-ulmi. Corchete et al. (9) had reported that the DED pathogen induced a large increase in PAL enzyme activity in DED-resistant $U$. pumila, but not in susceptible $U$. campestris suspension cultures. The increase observed in the resistant $U$. pumila reached its maximum at $24 \mathrm{hpi}$, which is earlier than the first significant increase we detected at $72 \mathrm{hpi}$ in the susceptible $U$. americana. Direct comparison of PAL gene expression and translation in susceptible and resistant elm cell cultures grown under similar conditions is needed in order to confirm the importance of an early PAL response in resistance.

In addition to its association with suberization, PAL participates in the production of phenylpropanoid-derived phytoalexins produced in plants in response to infection (12). PAL is also essential to the formation of cinnamic acid, which is involved in the biosynthetic pathway of flavonols, catechols, anthocyanidins, tannins, and lignin (13). Flavonoids, tannins, and lignin were characterized in infected elm callus in this study. Pijut et al. (38) observed deposits of phenolic-like structures in resistant, but not in susceptible $U$. americana callus tissues treated with culture filtrates of O. novo-ulmi. Krause et al. (26) later reported that electron-opaque phenolic-like material accumulated in both resistant and susceptible American elm callus tissue, but without identifying its nature. Our results confirmed that electron-opaque deposits accumulated in susceptible elm callus tissues inoculated with $O$. novo-ulmi. The use of histochemical tests with DMCA and vanillin enabled us to conclude that these deposits are indeed phenolics and contain a high proportion of less condensed tannins, such as catechins, and a certain proportion of condensed tannins, such as pro-anthocyanidins, that start accumulating at the later stages of infection. Some of the phenols shown in the present study possibly served as building blocks in the synthesis of lignin-like molecules, also observed here for the first time in elm callus tissues, as an additional barrier against the pathogen (6). The energy required for these biochemical transformations was likely derived from starch grains, which were abundant in numerous cells of inoculated callus samples. The large number of cells accumulating phenols and starch deposits as well as those showing walls enriched with lignin or suberin that are grouped together resembles, at a rudimentary stage, the compartmentalization walls which are frequently observed in infected trees (described in reviews $[36,46])$.

In summary, new aspects of the DED interaction were observed in vitro using susceptible American elm callus cultures inoculated with $O$. novo-ulmi. The homogeneity of the results obtained for the different callus lines used in the study shows the importance of these mechanisms and the reproducibility of the results. The pathogen was able to penetrate into host cells, likely through the secretion of cell wall degrading enzymes. The occurrence of defense reactions based on the accumulation of suberin, phenolics, and lignin was demonstrated unequivocally for the first time in elm callus tissues, and it was found to be associated with the upregulation of the PAL gene. Based on our findings, we expect elm callus cultures to be a useful system for identification and transcript profiling of other genes and pathways involved in the DED plant-pathogen interaction.

\section{ACKNOWLEDGMENTS}

This work was made possible thanks to Genomics and Strategic Grants from the Natural Sciences and Engineering Research Council (NSERC) of Canada. We thank V. Jacobi for insights and for critical revision of the manuscript and A. Vialle for technical assistance.

\section{LITERATURE CITED}

1. Bernards, M. A., Susag, L. M., Bedgar, D. L., Anterola, A. M., and Lewis, N. G. 2000. Induced phenylpropanoid metabolism during suberization and lignification: A comparative analysis. J. Plant Physiol. 15:601-607.

2. Bernier, L., Breuil, C., Hintz, W. E., Horgen, P. A., Jacobi, V., Dufour, J., Aoun, M., Bouvet, G., Kim, S. H., Diguistini, S., Tanguay, P., Eades, J., Burgess, S., de la Bastide, P., Pinchback, M., and Tadesse, Y. 2004. The Canadian Ophiostoma genome project. Invest. Agrar.: Sist. Recur. For. 13:105-117.

3. Bernier, L., and Hubbes, M. 1990. Mutations in Ophiostoma ulmi induced by $N$-methyl- $N{ }^{\prime}$-nitro- $N$-nitrosoguanidine. Can. J. Bot. 68:225-231.

4. Biggs, A. R.1984. Intracellular suberin: Occurrence and detection in tree bark. IAWA Bull. 5:243-248.

5. Biggs, A. R. 1985. Suberized boundary zones and the chronology of wound response in tree bark. Phytopathology 75:1191-1195.

6. Bird, P. M. 1988. The role of lignification in plant diseases. Pages 523536 in: Experimental and Conceptual Plant Phytopathology. R. S. Singh et al., eds. Oxford and IBH Publishing Co. Pvt. Ltd., New Delhi, India.

7. Campana, R. J. 1978. Inoculation and fungal invasion of the tree. Pages 17-20 in: Dutch Elm Disease, Perspectives After 60 Years, Vol. 8. W. A. Sinclair and R. J. Campana, eds. Plant Pathology, Cornell Univ. Agric. Exp. Stn., New York State Coll. Agric. Life Sci., Ithaca.

8. Chang, S., Puryear, J., and Cairney, J. 1993. A simple and efficient method for isolating RNA from pine trees. Plant Mol. Biol. Rep. 11:113116.

9. Corchete, M. P., Diez, J. J., and Valle, T. 1993. Phenylalanine ammonialyase activity in suspension cultures of Ulmus pumila and U. campestris treated with spores of Ceratocystis ulmi. Plant Cell Rep. 13:111-114.

10. Dai, G. H., Andary, C., Mondolot-Cosson, L., and Boubals, D. 1995. Involvement of phenolic compounds in the resistance of grapevine callus to downy mildew (Plasmopara viticola). Eur. J. Plant Pathol. 101:541547.

11. Diez, J., and Gil, L. 1998. Effects of Ophiostoma ulmi and Ophiostoma novo-ulmi culture filtrates on elm cultures from genotypes with different susceptibility to Dutch elm disease. Eur. J. For. Pathol. 28:399-407.

12. Dixon, R. A., Dey, P. M., and Lamb, C. J. 1983. Phytoalexins: Enzymology and molecular biology. Adv. Enzymol. Relat. Areas Mol. Biol. 55:1-136.

13. Dixon, R. A., and Paiva, N. L. 1995. Stress-induced phenylpropanoid metabolism. Plant Cell 7:1085-1097.

14. Domir, S. C., Schreiber, L. R., and Ichida, J. M. 1991. Factors affecting growth of Ophiostoma ulmi on elm callus tissue. J. Environ. Hort. 9:211215.

15. Domir, S. C., Schreiber, L. R., Ichida, J. M., and Eshita, S. M. 1992. Effect of elm selection, explant source and medium composition on growth of Ophiostoma ulmi on callus cultures. J. Environ. Hort. 10:59-62.

16. Duchesne, L. C., Hubbes, M., and Jeng, R. S. 1986. Mansonone E and F accumulation in Ulmus pumila resistant to Dutch elm disease. Can. J. For. Res. 16:410-412.

17. Duchesne, L. C., Jeng, R. S., and Hubbes, M. 1985. Accumulation of phytoalexins in Ulmus americana in response to infection by a nonaggressive and an aggressive strain of Ophiostoma ulmi. Can. J. Bot. 63:678-680.

18. Duchesne, L. C., Jeng, R. S., Hubbes, M., and Sticklen, M. B. 1994. Accumulations of mansonones $\mathrm{E}$ and $\mathrm{F}$ in elm callus cultures inoculated with Ophiostoma ulmi. Can J. Plant Pathol.16:118-121.

19. Eshita, S. M., Kamalay, J. C., Gingas, V. M., and Yaussy, D. A. 2000. Establishment and characterization of American elm cell suspension cultures. Plant Cell Tiss. Org. Cult. 61:245-249.

20. Et-Touil, A., Brasier, C. M., and Bernier, L., 1999. Localization of a pathogenicity gene in Ophiostoma novo-ulmi and evidence that it may be introgressed from O. ulmi. Mol. Plant-Microbe Interact. 12:6-15.

21. Et-Touil, A., Rioux, D., Mathieu, F. M., and Bernier, L. 2005. External symptoms and histopathological changes following inoculation of elms putatively resistant to Dutch elm disease with genetically close strains of Ophiostoma. Can. J. Bot. 83:656-667.

22. Ghanati, F., Morita, A., and Yokota, H. 2002. Induction of suberin and increase of lignin content by excess boron in tobacco cells. Soil Sci. Plant Nutr. 48:357-364.

23. Huntley, G. D. 1982. The elm - A resurgent resource or a persistent problem? Pages 103-111 in: Proceedings of Dutch Elm Disease, Symposium and Workshop. E. S. Kondo, Y. Hiratsuka, and W. B. G. Denyer, eds. Environment Canada, Canadian Forestry Service, and Province of Manitoba, Department of Natural Resources, Winnipeg, MB, Canada.

24. Jensen, W. A. 1962. Botanical Histochemistry: Principles and Practice. W.R. Freeman, San Francisco, CA.

25. Jones, D. H. 1984. Phenylalanine ammonia-lyase: Regulation of its induction, and its role in plant development. Phytochemistry 23:1349-1359. 
26. Krause, C. R., Ichida, J. M., Schreiber, L. R., and Domir, S. 1996. Hostparasite relationships of susceptible and resistant elm callus cultures challenged with Ophiostoma ulmi (Buisman) Nannf. J. Environ. Hort. 14:33-38.

27. Lee, S.-W., Nazar, R. N., Powell, D. A., and Robb, J. 1992. Reduced PAL gene suppression in Verticillium-infected resistant tomatoes. Plant Mol. Biol. 18:345-352.

28. Mittempergher, L., and Santini, A. 2004. The history of elm breeding. Invest. Agrar.: Sist. Recur. For. 13:161-177.

29. Mould, M. J. R., and Robb, J. 1992. The Colletotrichum trifolii-Medicago sativa interface, in culture: A cytological analysis. Can. J. Bot. 70:114124.

30. Mullick, D. B. 1975. A new tissue essential to necrophylactic periderm formation in the bark of four conifers. Can. J. Bot. 53:2443-2457.

31. Murashige, T., and Skoog, F. 1962. A revised medium for rapid growth and bioassays with tobacco tissue cultures. Physiol. Plant. 15:473-497.

32. Nasmith, C., Jeng, R., and Hubbes, M. 2008. A comparison of in vivo targeted gene expression during fungal colonization of DED-susceptible Ulmus americana. For. Pathol. 38:104-112.

33. Nicole, M., Chamberland, H., Nandris, D., and Ouellette, G. B. 1992. Cellulose is degraded during phloem necrosis of Hevea brasiliensis. Eur. J. For. Pathol. 22:266-277.

34. Oosterhaven, K., Hartmans, K. J., Scheffer, J. J. C., and Vanderplas, L. H. W. 1995. S-carvone inhibits phenylalanine ammonia lyase (PAL) activity and suberization during wound-healing of potato tubers. J. Plant Physiol. 146:288-294.

35. Ouellette, G. B. 1982. Comparative ultrastructural observations of reactions of xylem parenchyma cells to Ceratocystis ulmi infection in Ulmus spp. Pages 267-297 in: Proceedings of Dutch Elm Disease, Symposium and Workshop. E. S. Kondo, Y. Hiratsuka, and W. B. G. Denyer, eds. Environment Canada, Canadian Forestry Service, and Province of Manitoba, Department of Natural Resources, Winnipeg, MB, Canada.

36. Pearce, R. B. 1996. Antimicrobial defences in the wood of living trees. New Phytol. 132:203-233.

37. Pijut, P. M., Domir, S. C., Lineberger, R. D., and Schreiber, L. R. 1990. Use of culture filtrates of Ceratocystis ulmi as bioassay to screen for disease tolerant Ulmus americana. Plant Sci. 70:191-196.

38. Pijut, P. M., Lineberger, R. D., Domir, S. C., Ichida, J. M., and Krause, C. R. 1990. Ultrastructure of cells of Ulmus americana cultured in vitro and exposed to the culture filtrate of Ceratocystis ulmi. Phytopathology 80:764-767.

39. Reynolds, E. S. 1963. The use of lead citrate at high $\mathrm{pH}$ as an electronopaque stain in electron microscopy. J. Cell Biol. 17:208-212.

40. Rioux, D., Chamberland, H., Simard, M., and Ouellette, G. B. 1995. Suberized tyloses in trees: An ultrastructural and cytochemical study. Planta 196:125-140.

41. Rioux, D., and Ouellette, G. B. 1989. Light microscope observations of histological changes induced by Ophiostoma ulmi in various nonhost trees and shrubs. Can. J. Bot. 67:2335-2351.

42. Rioux, D., and Ouellette, G. B. 1991. Barrier zone formation in host and nonhost trees inoculated with Ophiostoma ulmi. I. Anatomy and histochemistry. Can. J. Bot. 69:2055-2073.

43. Rioux, D., and Ouellette, G. B. 1991. Barrier zone formation in host and nonhost trees inoculated with Ophiostoma ulmi. II. Ultrastructure. Can. J. Bot. 69:2074-2083.

44. Scheffer, R. J., and Elgersma, D. M. 1982. A scanning electron microscope study of cell wall degradation in elm wood by aggressive and nonaggressive isolates of Ophiostoma ulmi. Eur. J. For. Pathol. 12:25-28.

45. Schreiber, L. R., and Domir, S. C. 1994. Efficacy of criteria to identify aggressiveness in Ophiostoma ulmi and resistance in American elm germ plasm. Plant Dis. 78:629-632.

46. Shigo, A. L. 1984. Compartmentalization: A conceptual framework for understanding how trees grow and defend themselves. Annu. Rev. Phytopathol. 22:189-214.

47. Shigo, L., and Tippett, J. T. 1981. Compartmentalization of American elm tissues infected by Ceratocystis ulmi. Plant Dis. 65:715-718.

48. Simard, M., Rioux, D., and Laflamme, G. 2001. Formation of lignosuberized tissues in jack pine resistant to the European race of Gremmeniella abietina. Phytopathology 91:1128-1140.

49. Smalley, E. B., and Guries, R. P. 1993. Breeding elms for resistance to Dutch elm disease. Annu. Rev. Phytopathol. 31:325-352.

50. Strack, D. 1997. Phenolic metabolism. Pages 387-416 in: Plant Biochemistry. P. M. Dey and J. B. Harborne, eds. Academic Press, San Diego, CA.

51. Townsend, A. M., Bentz, S. E., and Johnson, G. R. 1995. Variation in response of selected American elm clones to Ophiostoma ulmi. J. Environ. Hort. 13:126-128.

52. Valette, C., Andary, C., Geiger, J. P., Sarah, J. L., and Nicole, M. 1998. Histochemical and cytochemical investigations of phenols in roots of banana infected by the burrowing nematode Radopholus similis. Phytopathology 88:1141-1148.

53. Wattendorff, J. 1974. Ultrahistochemical reactions of the suberized cell walls in Acorus, Acacia, and Larix. Z. Pflanzenphysiol. 73:214-225.

54. Woods, A. C., and Holmes, F. W. 1974. Extraction of fluid from healthy and Dutch elm-diseased elm branches using hydraulic compression. Phytopathology 64:1265-1267.

55. Woodward, S., and Pearce, R. B. 1988. Responses of Sitka spruce callus to challenge with wood decay fungi. Eur. J. For. Pathol. 18:217-229.

56. Yang, D., and Bernier, L. 1996. Production and use of calli from yellow birch buds for in vitro assessment of virulence of Nectria galligena isolates. Plant Cell Tiss. Org. Cult. 45:175-177.

57. Yang, D., Hubbes, M., Jr., Jeng, R. S., and Hubbes, M. 1994. A glycoprotein isolated from culture filtrates of Ophiostoma ulmi as a mansonone-inducing elicitor on elm callus. Mycol. Res. 98:295-300.

58. Yang, D., Jeng, R. S., and Hubbes, M. 1989. Mansonone accumulation in elm callus induced by elicitors of Ophiostoma ulmi, and general properties of elicitors. Can. J. Bot. 67: 3490-3497. 